\title{
Expression and prognostic relevance of MAGE-A3 and MAGE-C2 in non-small cell lung cancer
}

\author{
XINFENG CHEN $^{1,2^{*}}$, LIPING WANG ${ }^{1,2^{*}}$, JINYAN LIU $^{1}$, LAN HUANG $^{1,2}$, LI YANG $^{1,2}$, \\ QUN GAO $^{1,2}$, XIAOJUAN SHI ${ }^{1,2}$, JIEYAO LI ${ }^{1,2}$, FENG LI $^{1,2}$, ZHEN ZHANG $^{1}$, SONG ZHAO $^{3}$, \\ BIN ZHANG $^{4}$, PIERRE VAN DER BRUGGEN ${ }^{5}$ and YI ZHANG $^{1,2,6,7}$ \\ ${ }^{1}$ Biotherapy Center; ${ }^{2}$ Department of Oncology; ${ }^{3}$ Department of Cerebral Surgery, \\ The First Affiliated Hospital of Zhengzhou University, Zhengzhou, Henan 450052, P.R. China; \\ ${ }^{4}$ Division of Hematology-Oncology, Feinberg School of Medicine, Northwestern University, Chicago, IL 60611, USA; \\ ${ }^{5}$ Ludwig Institute for Cancer Research Brussels Branch, de Duve Institute, Université Catholique de Louvain, 1200 Brussels, \\ Belgium; ${ }^{6}$ School of Life Sciences, Zhengzhou University; \\ ${ }^{7}$ Engineering Key Laboratory for Cell Therapy of Henan, Zhengzhou, Henan 450052, P.R. China
}

Received October 2, 2015; Accepted November 21, 2016

DOI: $10.3892 / 01.2017 .5665$

\begin{abstract}
Melanoma-associated antigen (MAGE)-A3 and MAGE-C2 are antigens encoded by cancer-germline genes, and have been recognized as potential prognostic biomarkers and attractive targets for immunotherapy in multiple types of cancer. The present study aimed to analyze the clinicopathological significance of MAGE-A3/C2 expression in non-small cell lung cancer(NSCLC). The association betweenMAGE-A3/C2 mRNA and protein expression, and the pathological characteristics and overall survival of patients with NSCLC was analyzed. In addition, the functional role of MAGE-A3 in human NSCLC cell line A549 was examined in vitro. MAGE-A3/C2 mRNA expression was identified in $73 \%(151 / 206)$ and 53\% (109/206) of patients with NSCLC, respectively. MAGE-A3/C2 protein expression was identified in 58\% (44/76) and 53\% (40/76) of NSCLC cases, respectively. MAGE-A3 mRNA expression was observed to be associated with smoking history, disease stage and lymph node metastasis. However, no association was identified between MAGE-C2 mRNA expression and the clinicopathological characteristics of patients with NSCLC. MAGE-A3/C2-positive patients had a poorer survival rate compared with MAGE-A3/C2-negative patients. Multivariate analysis identified that MAGE-A3 expression may serve as an independent marker of poor prognosis in patients with NSCLC.
\end{abstract}

Correspondence to: Professor Yi Zhang, Biotherapy Center, The First Affiliated Hospital of Zhengzhou University, 1 Jianshe East Road, Zhengzhou, Henan 450052, P.R. China

E-mail: yizhang@zzu.edu.cn

*Contributed equally

Key words: non-small cell lung cancer, cancer-germline genes, epithelial-mesenchymal transition, prognostic biomarker
Downregulation of MAGE-A3 mRNA expression in A549 cells resulted in lower migration and colony formation rates, and a higher amount of epithelial marker and lower amount of mesenchymal marker expression compared with the control group. These results indicate that MAGE-A3 serves a role in NSCLC cell metastasis through the induction of epithelial-mesenchymal transition. In conclusion, MAGE-A3 may serve as a diagnostic and prognostic biomarker for patients with NSCLC, due to its association with tumor progression and poor clinical outcome.

\section{Introduction}

Lung cancer is one of the most frequently diagnosed types of cancer and the leading cause of cancer-associated mortality in males worldwide (1). The majority of lung cancer cases are classed as non-small cell lung cancer (NSCLC), which accounts for $\sim 85 \%$ of all lung cancer cases. Surgical resection, chemotherapy and radiotherapy are the primary therapeutic methods for the treatment of NSCLC; however, the 5-year survival rate in patients with NSCLC is $<15 \%$ (2), thus it is essential that novel diagnostic and therapeutic methods are developed. Recent clinical studies indicate the potential of immunotherapy for the treatment of lung cancer $(3,4)$.

The selection of a good therapeutic target is necessary to achieve a beneficial outcome through cancer immunotherapy. Antigens encoded by cancer-germline genes are considered potential targets for cancer immunotherapy, as they are expressed exclusively within immune-privileged germ cells and various malignancies (5). Immunotherapy that targets cancer-germline genes, such as MAGE-A3, represents a potential therapeutic approach for the treatment of NSCLC (6). In addition, MAGE-A3 antigen-specific T-cell receptor (TCR) modified T-cell therapy has been demonstrated to effectively kill lung cancer cells (7).

As of 2013, 265 cancer-germline genes have been identified, 105 of which are located on the $\mathrm{X}$ chromosome (8); 
however, their biological function in tumors remains poorly understood. Cancer-germline genes are considered important factors in oncogenesis, influencing the immortality, invasiveness, immune evasion capability and metastatic capacity of tumor cells (9). Downregulation of cancer-germline gene expression could modify tumor cell morphology, adhesion and migration $(10,11)$. Malignant tissues frequently coexpress several cancer-germline genes, whose expression levels are associated with advanced tumor stage and poor patient prognosis (9). Antigens encoded by cancer-germline genes are considered potential markers of poor prognosis and attractive targets for immunotherapy in various cancers $(12,13)$. Lung cancer frequently exhibits expression of these genes. Several studies have investigated the mRNA and protein expression of cancer-germline genes in lung cancer (14-19). Cancer-germline gene expression is induced through promoter demethylation by DNA demethylation agents $(15,20,21)$. MAGE-A3 and MAGE-C2 (MAGE-A3/C2) have been recognized as attractive potential targets for cancer immunotherapy (22-27). Previous studies have indicated that overexpression of MAGE-A3/C2 is associated with tumor metastasis and poor clinical outcome $(28,29)$. However, the expression and prognostic significance of MAGE-A3/C2 in NSCLC remains unclear.

In the present study, the frequency of MAGE-A3/C2 expression at the mRNA and protein level in NSCLC samples was detected. The association between MAGE-A3/C2 expression and the clinicopathological characteristics, in addition to the overall survival, of patients with NSCLC was subsequently evaluated. In addition, the underlying mechanisms through which MAGE-A3 expression influences NSCLC cell biology were investigated in vitro.

\section{Materials and methods}

Cell line and tumor samples. The human NSCLC cell line A549 was purchased from Shanghai Cell Bank, Chinese Academy of Sciences (Shanghai, China), and was cultured in RMPI 1640 medium (Gibco; Thermo Fisher Scientific, Inc., Waltham, MA, USA) supplemented with $10 \%$ fetal calf serum (FBS; Hyclone; GE Healthcare, Logan, UT, USA), penicillin (100 U/ml), and streptomycin $(100 \mu \mathrm{g} / \mathrm{ml})$. The cell culture was maintained at $37^{\circ} \mathrm{C}$ with $5 \% \mathrm{CO}_{2}$ in a humidified atmosphere. A total of 206 NSCLC specimens and paired adjacent healthy lung tissue samples were collected at the First Affiliated Hospital of Zhengzhou University (Zhengzhou, China) between November 2012 and December 2013 (first cohort). The sample collection process was approved by the First Affiliated Hospital of Zhengzhou University Ethics Committee and informed consent was obtained from each patient. None of the patients received preoperative chemotherapy or radiotherapy. A total of 76 formalin-fixed, paraffin-embedded (FFPE) NSCLC tissue samples and 7 corresponding adjacent healthy tissue samples were obtained from the Department of Pathology at the First Affiliated Hospital of Zhengzhou University from patients who were diagnosed with NSCLC between September 2008 and August 2009 (second cohort). Lung cancer is staged according to the system advocated by the American Joint Committee on Cancer and the Union for International Cancer Control, which as of 2010 is in its 7th edition (30,31). Details of the clinicopathological characteristics of patients from the two cohorts are detailed in Table I.

Reverse transcription-polymerase chain reaction (RT-PCR) and quantitative $(q) P C R$. Total RNA was isolated using TRIzol reagent according to the manufacturer's instructions (Invitrogen; Thermo Fisher Scientific, Inc.). The concentration and purity of all samples were verified using NanoDrop2000 (Thermo Fisher Scientific, Inc.). cDNA was obtained using a PrimeScript ${ }^{\mathrm{TM}}$ RT reagent kit (Takara Bio, Inc., Otsu, Japan) according to the manufacturer's instructions. Briefly, samples containing $1 \mu \mathrm{g}$ total RNA were incubated with $1 \mu \mathrm{l}$ gDNA Eraser, $2 \mu 1$ 5X gDNA eraser buffer and RNase-free $\mathrm{dH}_{2} \mathrm{O}$ at $42^{\circ} \mathrm{C}$ for $2 \mathrm{~min}$. After adding the enzyme mix, the reaction was incubated at $37^{\circ} \mathrm{C}$ for $15 \mathrm{~min}$. The cDNA was amplified using Premix Tap (Takara Bio, Inc.) and glyceraldehyde 3-phosphate dehydrogenase (GAPDH) was used as a loading control. The initial step was performed at $94^{\circ} \mathrm{C}$ for $5 \mathrm{~min}$, the amplification was performed for 35 cycles of denaturation at $95^{\circ} \mathrm{C}$ for $30 \mathrm{sec}$, annealing at $58^{\circ} \mathrm{C}$ for $30 \mathrm{sec}$ and elongation at $72^{\circ} \mathrm{C}$ for $30 \mathrm{sec}$. Following the last cycle, a terminal elongation step $\left(5 \mathrm{~min}\right.$ at $\left.72^{\circ} \mathrm{C}\right)$ was added and then the samples were kept at $4^{\circ} \mathrm{C}$. The PCR products were separated on $1.5 \%$ agarose gel stained with ethidium bromide and recorded. The expected sizes of GAPDH, MAGE-A3 and MAGE-C2 RT-PCR products were 233, 239 and $189 \mathrm{bp}$, respectively. PCR products from samples positive for MAGE-A3/C2 were sequenced by Sangon Biotech Co., Ltd. (Shanghai, China). qPCR was performed using SYBR Premix Ex Taq II (Takara Bio, Inc.) and an Mx3005P qPCR system (Agilent Technologies, Inc., Santa Clara, CA, USA), in order to quantify the mRNA expression of MAGE-A3 and epithelial-mesenchymal transition (EMT) markers in A549 cells transfected with scrambled small interfering RNA (siRNA) and siRNA targeting MAGE-A3 after $48 \mathrm{~h}$. The thermal cycling conditions included an initial denaturation for $30 \mathrm{sec}$ at $95^{\circ} \mathrm{C}$ and 40 cycles consisting of an annealing step at $95^{\circ} \mathrm{C}$ for $5 \mathrm{sec}$ and an extension step at $60^{\circ} \mathrm{C}$ for $20 \mathrm{sec}$. Each sample was analyzed in triplicate. The abundance of mRNA for each gene of interest was normalized to GAPDH. Each sample obtained from three independent experiments was used for analysis of relative gene expression using the 2- $\Delta \Delta \mathrm{Cq}$ method (32). mRNAs being quantified and their primers sequences are illustrated in Table II.

Immunohistochemistry (IHC). MAGE-A3/C2 protein staining was performed using 4- $\mu$ m-thick sections of FFPE tissues. Sections were treated with $3 \% \mathrm{H}_{2} \mathrm{O}_{2}$ and $5 \%$ bovine serum albumin for $30 \mathrm{~min}$ at room temperature, and then incubated with anti-human MAGE-A3 (1:150 dilution; catalog no. ab140678; Abcam, Cambridge, UK) and MAGE-C2 (1:400 dilution; catalog no. ab209667, Abcam) primary antibodies overnight at $4^{\circ} \mathrm{C}$. Following incubation with horseradish peroxidase-conjugated secondary antibody for $1 \mathrm{~h}$ at room temperature, the sections were washed and counterstained with hematoxylin and visualized under a microscope (Olympus, Tokyo, Japan). Samples were considered positive for MAGE-A3/C2 following the detection of any nuclear and/or cytoplasmic antibody signal in the tumor cells. Samples with complete absence of antibody signal were considered 
negative for each MAGE tested. Detection of MAGE-A3/C2 expression in testis tissue was used as a positive control and samples that underwent the same process with the absence of primary antibody treatment were used as a negative control.

Flow cytometry and sequence-specific primer (SSP)-PCR. Expression of human leukocyte antigen (HLA)-A2 on peripheral blood mononuclear cells (PBMCs) from cohort 1 patients was detected using flow cytometry and verified through SSP-PCR. PBMCs were incubated with phycoerythrin-conjugated mouse anti-human HLA-A2 monoclonal antibody (catalog no. 343305; BD Biosciences, Franklin Lakes, NJ, USA), at an appropriate concentration $\left(\sim 5 \times 10^{5}\right.$ cells were resuspended in $100 \mu \mathrm{l}$ PBS and added to $2 \mu \mathrm{l}$ anti-human HLA-A2 antibody) according to the manufacturer's instructions, for $15 \mathrm{~min}$ at $4^{\circ} \mathrm{C}$ in the dark. Samples were analyzed by flow cytometry (BD FACSCanto II; BD Biosciences). The results were also verified by SSP-PCR using two pairs of HLA-A2 primers (Table II).

siRNA-mediated gene knockdown. Scrambled negative control siRNA (Scrambled siRNA sense, 5'-UUC UCC GAA CGU GUC ACG UTT-3' and antisense, 5'-ACG UGA CAC GUU CGG AGA ATT-3') and siRNA targeting MAGE-A3 (si-MAGE-A3 sense, 5'-CAG UGA UCC UGC AUG UUA UTT-3' and antisense, 5'-AUA ACA UGC AGG AUC ACU GTT-3') were provided by Shanghai GenePharma (Shanghai, China). Transfection siRNA into NSCLC cells was performed using Lipofectamine ${ }^{\circledR} 3000$ reagent (Invitrogen; Thermo Fisher Scientific, Inc.) at a final concentration of $36 \mathrm{nM}$. The efficiency of siRNA knockdown was subsequently confirmed using qPCR (as aforementioned).

Cell apoptosis and colony formation assays. Following NSCLC cell siRNA transfection, as described above, for $48 \mathrm{~h}, 1 \times 10^{5}$ transfected cells were collected and centrifuged at $300 \mathrm{x} g$ at room temperature for $10 \mathrm{~min}$. Thereafter, cells incubated with AlexaFluor647 Annexin V (BioLegend, Inc. San Diego, CA, USA) for $15 \mathrm{~min}$ at $4^{\circ} \mathrm{C}$ in the dark, and propidium iodide (PI; Sigma-Aldrich; Merck Millipore, Darmstadt, Germany) was added. Samples were immediately analyzed by flow cytometry (BD FACSCanto II; BD Biosciences). For the colony formation assay, cells transfected with specific or scrambled si-RNA were plated on 6-well plates (Costar; Corning, Inc., NY, USA) at a density of 1,000/well maintained in RPMI-1640 medium containing 10\% FBS and $4 \mu \mathrm{g} / \mathrm{ml}$ heparin (Sigma-Aldrich; Merck Millipore), B27 (1:50 dilution; Gibco; Thermo Fisher Scientific, Inc.), $20 \mathrm{ng} / \mathrm{ml}$ EGF, $20 \mathrm{ng} / \mathrm{ml}$ basic fibroblast growth factor (both Sigma-Aldrich; Merck Millipore), $100 \mathrm{IU} / \mathrm{ml}$ penicillin and $100 \mu \mathrm{g} / \mathrm{ml}$ streptomycin for 7 days. The colonies were counted under a low magnification microscope (Leica Microsystems, GmbH, Wetzlar, Germany) and a group of $>30$ cells or a diameter of $>1 \mathrm{~mm}$ in each well was defined as a colony.

Cell migration assay. Cell migration was assessed in 24-well Boyden Chambers (Corning, Inc.) according to the manufacturer's protocol. Cells that migrated to the underside of the membranes of each insert were counted at X100 magnification
Table I. Clinicopathological characteristics of patients with non-small cell lung cancer.

\begin{tabular}{lrc}
\hline & \multicolumn{2}{c}{ Number of patients $(\%)$} \\
\cline { 2 - 3 } $\begin{array}{l}\text { Clinicopathological } \\
\text { characteristic }\end{array}$ & $\begin{array}{c}\text { Cohort } 1 \\
(\mathrm{n}=206)\end{array}$ & $\begin{array}{c}\text { Cohort } 2 \\
(\mathrm{n}=76)\end{array}$ \\
\hline Age at diagnosis (years old) & & \\
$<65$ & $143(69)$ & $50(66)$ \\
$\geq 65$ & $63(31)$ & $26(34)$ \\
Gender & & \\
Male & $141(68)$ & $50(66)$ \\
Female & $65(32)$ & $26(34)$ \\
Histological grade & & $18(24)$ \\
G1 & $26(13)$ & $44(58)$ \\
G2 & $115(55)$ & $14(18)$ \\
G3 & $65(32)$ & \\
Histological type & & $36(47)$ \\
Squamous cell carcinoma & $75(36)$ & $40(53)$ \\
Adenocarcinoma & $131(64)$ & $36(47)$ \\
Lymph node metastasis & & $40(53)$ \\
Absent & $70(34)$ & \\
Present & $136(66)$ & \\
Tumor stage & & \\
I-II & & \\
III-IV & & \\
\hline
\end{tabular}

Cohort 1 were assessed by reverse transcription-quantitative polymerase chain reaction and cohort 2 were assessed by immunohistochemistry. G, grade.

in five random areas under a low magnification microscope (Leica Microsystems GmbH).

Statistical analysis. Statistical analysis was performed using SPSS software (version 17.0; SPSS, Inc., Chicago, IL, USA). Pearson's chi-squared test was used to evaluate the association between MAGE-A3/C2 expression and the clinicopathological characteristics of patients with NSCLC. The Kaplan-Meier estimator was performed to evaluate the overall survival of patients. Univariate and multivariate Cox's proportional hazard regression model analysis were used to evaluate the prognostic significance of MAGE-A3/C2 expression in NSCLC. All experiments were repeated three times and results are expressed as the mean \pm standard deviation. $\mathrm{P}<0.05$ was considered to indicate a statistically significant difference.

\section{Results}

Association between MAGE-A3/C2 mRNA expression and the clinicopathological characteristic of patients with NSCLC. MAGE-A3/C2 mRNA expression was analyzed in 206 lung cancer tissue and paired adjacent lung tissue samples from patients with NSCLC (cohort 1) using RT-PCR. MAGE-A3/C2 was not expressed in paired adjacent healthy lung tissue, but 
Table II. Primers used for polymerase chain reaction analysis.

Gene

GAPDH

\section{Forward \\ Reverse \\ MAGE-A3 \\ Forward \\ Reverse \\ MAGE-C2}

Forward

Reverse

HLA-A2-internal ${ }^{a}$

Forward

Reverse

HLA-A2-outer

Forward

Reverse

E-cadherin

Forward

Reverse

N-cadherin

Forward

Reverse

Vimentin

Forward

Reverse

SLUG

Forward

Reverse
5'-GGAGCCAAAAGGGTCATCATCTC-3'

5'-GAGGGGCCATCCACAGTCTTCT-3'

5'-AGTCCGAGTTCCAAGCAG-3'

5'-GCAGGTGGCAAAGATGTA-3'

5'-TGAGTTAGAAGACTGGGTAGATGC-3'

5'-ATGCTCTCGGTAAGATTTGGTATC-3'

5'-GCGCCGTGGAAGAGGGTCG-3'

5'-CCCGTCCCAATACTCCCGA-3'

5'-GGTCCGGAGTATTGGGACG-3'

5'-GTGCTTGGTGGTCTGAGCT-3'

5'-TGCCCAGAAAATGAAAAAGG-3'

5'-GTGTATGTGGCAATGCGTTC-3'

5'-ACAGTGGCCACCTACAAAGG-3'

5'-CCGAGATGGGGTTGATAATG-3'

163

5'-GAGAACTTTGCCGTTGAAGC-3'

5'-GCTTCCTGTAGGTGGCAATC-3'

158

5'-GGGGAGAAGCCTTTTTCTTG-3'

5'-TCCTCATGTTTGTGCAGGAG-3'

${ }^{a}$ CDNA was first amplified using the HLA-A2-outer primer, then the product was used in amplification using the HLA-A2-internal primer. MAGE, melanoma-associated antigen; HLA, human leukocyte antigen; E-cadherin, epithelial-cadherin; N-cadherin, neural-cadherin; SLUG, snail family transcriptional repressor 2; bp, base pairs.

was frequently expressed in corresponding NSCLC tissues (Fig. 1A). The RT-PCR products from three MAGE-A3/C2 positive samples were subsequently sequenced. The obtained sequences had high intra-isolate and inter-isolate nucleotide consistency. Expression of MAGE-A3 and MAGE-C2 mRNA was identified in 73 and $53 \%$ of NSCLC cases, respectively. The association between MAGE-A3/C2 expression and the clinicopathological characteristics of patients with NSCLC are illustrated in Table III. Positive MAGE-A3 mRNA expression was significantly associated with lymph node metastasis and stage III-IV disease. A higher frequency of MAGE-A3 was found in patients with lymph node metastasis at diagnosis (84\%) compared with patients without lymph node metastasis at diagnosis $(68 \%)(\mathrm{P}=0.012)$. In total, $60 \%$ of patients with stage I, $68 \%$ of patients with stage II and $90 \%$ of patients with stage III-IV disease expressed MAGE-A3 ( $\mathrm{P}=0.006)$. However, MAGE-C2 mRNA expression was not significantly associated with any clinicopathological characteristics. These results indicate that MAGE-A3 is associated with the development and progression of NSCLC, suggesting it is a biomarker of poor patient prognosis.

Coexpression analysis of MAGE-A3 and MAGE-C2 in NSCLC tissue revealed that at least one of the MAGEs analyzed were expressed in $82 \%$ of samples. Coexpression of MAGE-A3 and MAGE-C2 was identified in $45 \%$ of samples (data not shown). The frequency of coexpression was significantly higher in patients that were $<65$ years old $(\mathrm{P}=0.002)$ and those with advanced disease stage $(\mathrm{P}=0.014)$ (Table III). A statistically significant pattern of coexpression between MAGE-A3 and MAGE-C2 was also identified ( $\mathrm{P}=0.0001$; data not shown). These results suggest that $82 \%$ of patients with NSCLC would be eligible for antigen-specific immunotherapeutic approaches targeting MAGE-A3 or MAGE-C2.

Percentage of samples coexpressing HLA-A2 and $M A G E-A 3 / C 2$. Among cohort 1 patients with NSCLC, $47 \%$ of 


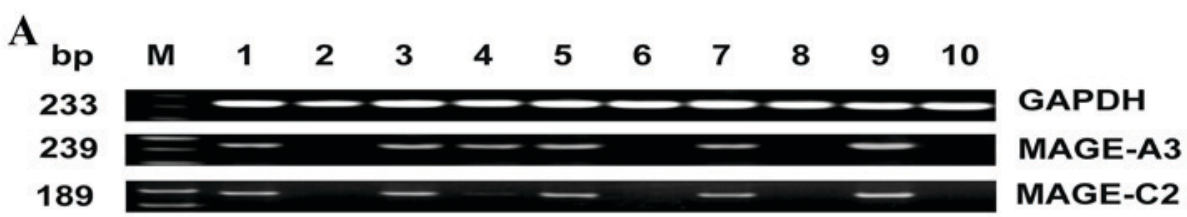

B

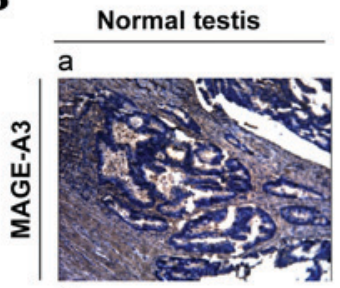

d

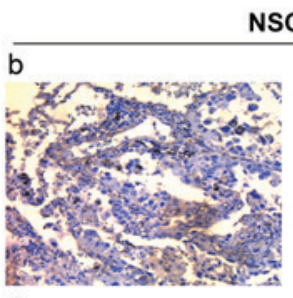

NSCLC

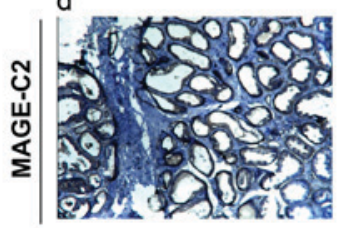

e
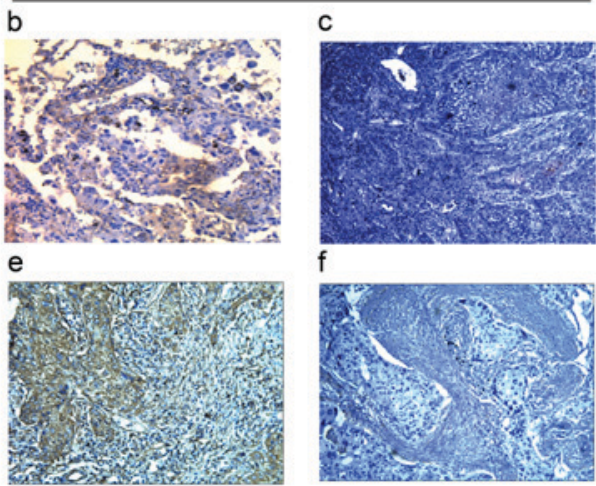

f

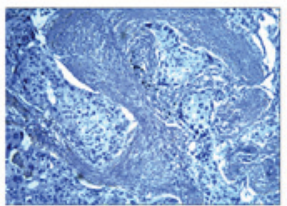

Figure 1. Representative mRNA and protein expression of MAGE-A3/C2 in NSCLC tissues. (A) Agarose gel electrophoresis of reverse transcription polymerase chain reaction results for MAGE-A3/C2 mRNA expression in NSCLC samples. GAPDH was used as an internal control. Lanes: M, marker; 1, normal testis tissue used as a positive control; 2, healthy lung tissue; 3-10, NSCLC tissues. (B) Immunohistochemical analysis of MAGE-A3/C2 protein expression in NSCLC specimens. (B) Tumor staining with monoclonal antibodies against MAGE-A3/C2. a, MAGE-A3 positive normal testis sample (positive control); b, MAGE-A3-positive NSCLC sample; c, MAGE-A3-negative NSCLC sample; d, MAGE-C2-positive normal testis sample (positive control); e, MAGE-C2-positive NSCLC samples; f, MAGE-C2-negative NSCLC sample. Magnification, x200. MAGE, melanoma-associated antigen; NSCLC, non-small cell lung cancer; bp, base pairs.

samples expressed HLA-A2, 37\% coexpressed HLA-A2 and MAGE-A3, and 26\% coexpressed HLA-A2 and MAGE-C2 (data not shown). A previous study revealed that $29 \%$ of patients with NSCLC coexpressed HLA-A2 and MAGE-A3 in a Japanese cohort (12). Patients with coexpression of HLA-A2 and MAGE-A3/C2 may benefit from HLA-A2 restricted peptide vaccination or antigen-specific TCR modified T cell therapy. The redirection of T cell targeting through TCR gene modification has been demonstrated to be a valuable strategy for cancer immunotherapy (33).

Expression of MAGE-A3 $m R N A$ is increased in male smokers with NSCLC. MAGE-A3 mRNA expression was identified in $76 \%$ of male patients (cohort 1; $n=141$; Table III). Furthermore, $72 \%(101 / 141)$ of male patients had a prolonged smoking history (>20 years). MAGE-A3 mRNA was demonstrated to be expressed in $81 \%$ of male smokers with NSCLC and $63 \%$ of male non-smokers. MAGE-A3 mRNA expression was significantly correlated with the pack-year smoking history of the male patients $(\mathrm{P}=0.019$; data not shown), indicating that male patients with a history of smoking may have a poorer prognosis compared with male non-smokers and could benefit from MAGE-A3 targeted immunotherapy.

Correlation between MAGE-A3/C2 expression and the overall survival of patients with NSCLC. To assess the association between MAGE-A3/C2 protein expression and the overall survival of patients with NSCLC, the protein expression of MAGE-A3 and MAGE-C2 in NSCLC cancer tissues (cohort 2) was detected using IHC. Representative results are illustrated in Fig. 1B. MAGE-A3/C2 protein was absent in healthy adjacent lung tissue samples. In cancerous tissue samples, 58\% (44/76) and 53\% (40/76) were positive for MAGE-A3 and MAGE-C2 protein expression, respectively (data not shown). The majority of immunoreactivity to MAGE-A3/C2 was observed in the cytoplasm, with fewer nuclei stained. The association between MAGE-A3/C2 protein expression and the clinicopathological characteristics of patients with NSCLC in cohort 2 was subsequently analyzed (Table IV). MAGE-A3 protein expression was identified to be significantly correlated with lymph node metastasis $(\mathrm{P}=0.044)$ and tumor stage $(\mathrm{P}=0.038)$, as $48 \%(19 / 40)$ of non-lymph node metastasis and $70 \%(25 / 36)$ of lymph node metastasis cancer tissue samples were MAGE-A3 positive. In addition, $48 \%$ (20/42) of stage I-II and 71\% (24/34) of stage III-IV tumors were MAGE-A3 positive. There was no statistically significant association between MAGE-C2 protein expression and tumor stage $(\mathrm{P}=0.271)$. Coexpression of MAGE-A3 and MAGE-C2 protein was identified in $26 \%$ (28/76) of NSCLC samples and was significantly correlated with tumor stage $(\mathrm{P}=0.030)$.

The association between MAGE-A3/C2 expression and the overall survival of patients was analyzed. Regarding MAGE-A3 expression, 32/76 patients who did not express MAGE-A3 were identified and 9 succumbed to mortality (median survival time, 48 months; data not shown). A total of 44/76 patients who expressed MAGE-A3 were identified and 31 succumbed to mortality (median survival time, 24 months; data not shown). Overall survival was significantly negatively correlated with MAGE-A3 expression ( $\mathrm{P}=0.0002$; Fig. 2A). For MAGE-C2 expression, 36/76 patients who did not express MAGE-C2 were identified and 15 succumbed to mortality (median survival time, 49 months; data not shown). A total of 40/76 patients with MAGE-C2 expression were identified and 25 succumbed to mortality (median survival time, 24 months; 
Table III. Association between MAGE-A3/C2 mRNA expression and the clinicopathological characteristics of patients with non-small cell lung cancer in cohort 1.

Cancer germline gene-expressing samples (\%)

Clinicopathological

characteristic

\begin{tabular}{|c|c|c|c|c|c|}
\hline MAGE-A3 & P-value & MAGE-C2 & P-value & $\begin{array}{c}\text { MAGE-A3/C2 } \\
\text { coexpression }\end{array}$ & P-value \\
\hline 74 & 0.733 & 57 & 0.072 & 50 & $0.002^{\mathrm{a}}$ \\
\hline 71 & & 44 & & 33 & \\
\hline 76 & 0.238 & 50 & 0.109 & 43 & 0.228 \\
\hline 68 & & 60 & & 50 & \\
\hline 69 & 0.694 & 50 & 0.872 & 39 & 0.310 \\
\hline 72 & & 52 & & 42 & \\
\hline 77 & & 55 & & 52 & \\
\hline 76 & 0.624 & 47 & 0.112 & 40 & 0.192 \\
\hline 72 & & 57 & & 47 & \\
\hline 84 & $0.012^{\mathrm{a}}$ & 53 & 0.554 & 53 & 0.061 \\
\hline 68 & & 53 & & 440 & \\
\hline 66 & $0.006^{\mathrm{a}}$ & 52 & 0.853 & 39 & $0.014^{\mathrm{a}}$ \\
\hline 79 & & 54 & & 54 & \\
\hline 90 & & 56 & & 56 & \\
\hline 77 & 0.270 & 56 & 0.272 & 47 & 0.503 \\
\hline 70 & & 51 & & 42 & \\
\hline
\end{tabular}

Age at diagnosis (years)

$<65$

$\geq 65$

74

Gender

Male

Female

Histological grade

$\begin{array}{ll}\text { G1 } & 69 \\ \text { G2 } 3 & 72\end{array}$

Histological type

Squamous cell carcinoma

Adenocarcinoma

Lymph node metastasis

Present

Absent

Tumor stage

I

II

III-IV

66

HLA-A2 expression

Positive

70

${ }^{\mathrm{a}} \mathrm{P}<0.05$. MAGE, melanoma-associated antigen; HLA, human leukocyte antigen.
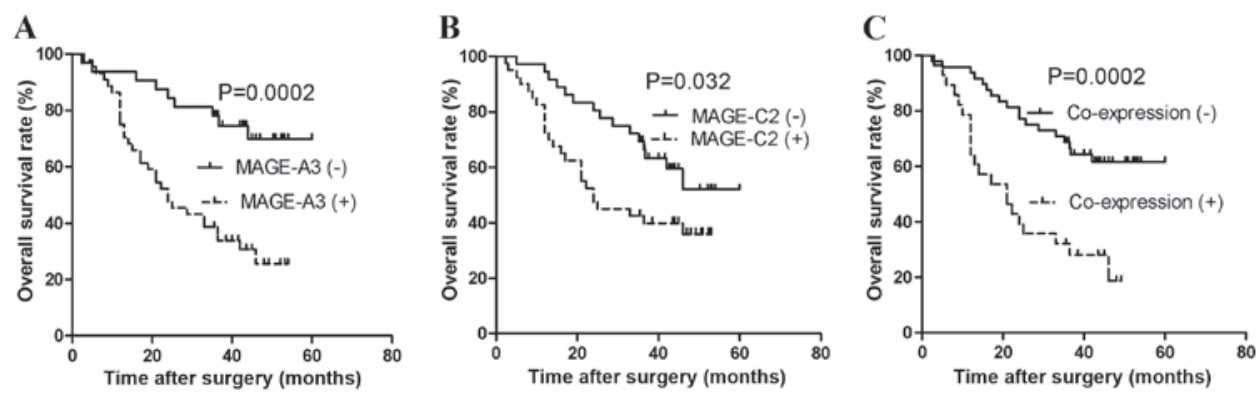

Figure 2. Kaplan-Meier estimator overall survival curves for patients with NSCLC. Overall survival of patients with NSCLC who underwent surgical resection based on expression of (A) MAGE-A3, (B) MAGE-C2 and (C) MAGE-A3 and MAGE-C2. MAGE, melanoma-associated antigen; NSCLC, non-small cell lung cancer.

data not shown). In addition, overall survival was significantly negatively correlated with MAGE-C2 expression $(\mathrm{P}=0.032$; Fig. 2B). Coexpression of MAGE-A3 and MAGE-C2 was also correlated with a poorer overall survival of patients with NSCLC ( $\mathrm{P}=0.0002$; Fig. 2C). In addition, multivariate analysis demonstrated that MAGE-A3 expression was an independent predictor of poor prognosis (hazard ratio, 3.226;
95\% confidence interval, 1.446-7.918; $\mathrm{P}=0.004$; Table V). This indicates that MAGE-A3 is a marker of poor prognosis in patients with NSCLC.

MAGE-A3 siRNA knockdown. Clinicopathological data analysis demonstrated that MAGE-A3 expression was significantly correlated with advanced tumor stage $(\mathrm{P}=0.006$; Table III) and 
Table IV. Association between MAGE-A3/C2 protein expression and the clinicopathological characteristics of patients with non-small cell lung cancer in cohort 2 .

\begin{tabular}{|c|c|c|c|c|c|c|}
\hline \multirow[b]{2}{*}{$\begin{array}{l}\text { Clinicopathological } \\
\text { characteristic }\end{array}$} & \multicolumn{6}{|c|}{ Number of samples (\%) } \\
\hline & MAGE-A3 & P-value & MAGE-C2 & P-value & $\begin{array}{l}\text { MAGE-A3/C2 } \\
\text { co-expression }\end{array}$ & P-value \\
\hline \multicolumn{7}{|l|}{ Gender } \\
\hline Male & 52 & 0.115 & 58 & 0.145 & 36 & 0.513 \\
\hline Female & 69 & & 42 & & 39 & \\
\hline \multicolumn{7}{|l|}{ Age (years) } \\
\hline$<65$ & 62 & 0.223 & 56 & 0.535 & 40 & 0.296 \\
\hline$\geq 65$ & 50 & & 46 & & 31 & \\
\hline \multicolumn{7}{|l|}{ Lymph node metastasis } \\
\hline Present & 69 & $0.044^{\mathrm{a}}$ & 61 & 0.120 & 53 & 0.143 \\
\hline Absent & 46 & & 53 & & 40 & \\
\hline \multicolumn{7}{|l|}{ Histological grade } \\
\hline G1 & 67 & 0.503 & 50 & 0.292 & 39 & 0.172 \\
\hline G2 & 52 & & 48 & & 30 & \\
\hline G3 & 64 & & 71 & & 57 & \\
\hline \multicolumn{7}{|l|}{ Histological type } \\
\hline Squamous cell carcinoma & 59 & 0.535 & 62 & 0.144 & 41 & 0.320 \\
\hline Adenocarcinoma & 57 & & 45 & & 35 & \\
\hline \multicolumn{7}{|l|}{ Tumor stage } \\
\hline I & 45 & $0.038^{\mathrm{a}}$ & 42 & 0.271 & 24 & $0.030^{\mathrm{a}}$ \\
\hline II & 56 & & 67 & & 33 & \\
\hline III-IV & 71 & & 59 & & 50 & \\
\hline
\end{tabular}

${ }^{\mathrm{a}}<<0.05$. MAGE, melanoma-associated antigen.

Table V. Univariate and multivariate analyses of clinicopathological characteristics associated with overall survival in cohort 2 patients with non-small cell lung cancer.

\begin{tabular}{|c|c|c|c|c|c|c|}
\hline \multirow{2}{*}{$\begin{array}{l}\text { Clinicopathological } \\
\text { characteristic }\end{array}$} & \multicolumn{3}{|c|}{ Univariate analysis } & \multicolumn{3}{|c|}{ Multivariate analysis } \\
\hline & HR & CI $(95 \%)$ & P-value & HR & CI $(95 \%)$ & P-value \\
\hline Age & 1.158 & $0.576-2.328$ & 0.679 & 1.342 & $0.617-2.919$ & 0.458 \\
\hline Gender & 0.865 & $0.453-1.652$ & 0.660 & 0.962 & $0.425-2.177$ & 0.926 \\
\hline Histological type & 1.879 & $0.995-3.545$ & 0.052 & 1.057 & $0.416-3.879$ & 0.364 \\
\hline Lymph node metastasis & 3.077 & $1.575-6.011$ & $0.001^{\mathrm{a}}$ & 0.343 & $0.083-1.418$ & 0.140 \\
\hline Tumor stage & 2.159 & $1.475-3.162$ & $0.000^{\mathrm{a}}$ & 3.505 & $1.582-7.766$ & $0.002^{\mathrm{a}}$ \\
\hline Histological grade & 0.971 & $0.568-1.659$ & 0.914 & 0.733 & $0.416-1.290$ & 0.281 \\
\hline MAGE-A3 & 4.129 & $1.888-9.030$ & $0.000^{\mathrm{a}}$ & 3.226 & $1.446-7.918$ & $0.004^{\mathrm{a}}$ \\
\hline MAGE-C2 & 2.143 & $1.111-4.133$ & $0.032^{\mathrm{a}}$ & 1.909 & $0.954-3.821$ & 0.068 \\
\hline
\end{tabular}

${ }^{\mathrm{a}} \mathrm{P}<0.05$. MAGE, melanoma-associated antigen; HR, hazard ratio; $\mathrm{CI}$, confidence interval.

poor patient prognosis $(\mathrm{P}=0.0002$; Fig. $2 \mathrm{~A})$, indicating that MAGE-A3 expression contributes to tumor metastasis and invasion. Thus, siRNA knockdown was performed to identify the function of MAGE-A3 in NSCLC cells. High-level MAGE-A3 mRNA expression in the NSCLC cell line A549 cells was confirmed, and siRNA specific to MAGE-A3 was purchased and tested (data not shown). A total of $48 \mathrm{~h}$ post-transfection, si-MAGE-A3 downregulated MAGE-A3 expression by $80-90 \%$ compared with cells transfected with scrambled siRNA ( $\mathrm{P}=0.0018$; Fig. $3 \mathrm{~A})$. 
A

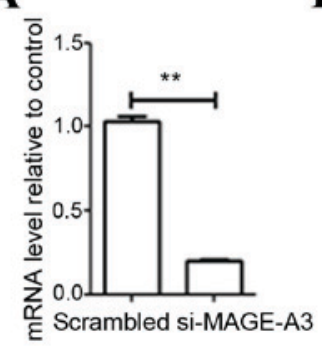

B

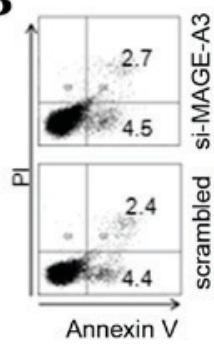

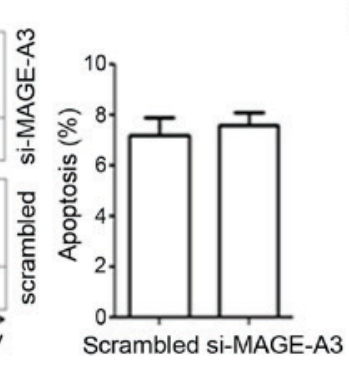
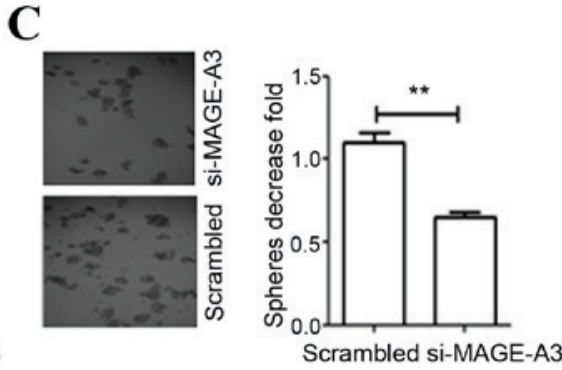

D

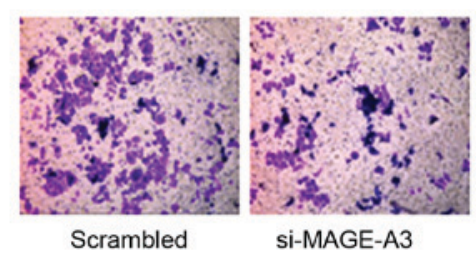

$\mathbf{E} \overline{\mathrm{g}}$

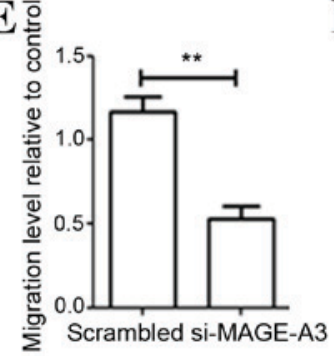

$\mathbf{F}$

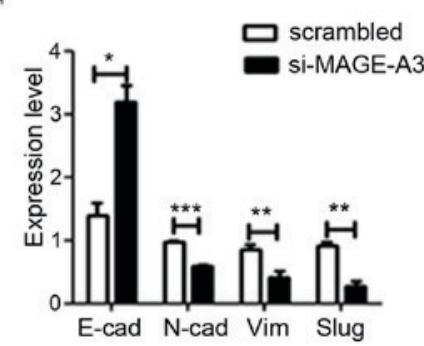

Figure 3. Effect of MAGE-A3 knockdown on A549 cells. (A) Evaluation of efficiency of si-mediated MAGE-A3 knockdown via qRT-PCR analysis. (B) Effect of MAGE-A3 knockdown on cell apoptosis was detected through flow cytometry and quantified. (C) Depletion of MAGE-A3 inhibited cell colony formation. (D) Representative distinction of migration in A549 cells treated by scrambled and specific MAGE-A3 siRNA. (E) Downregulation of MAGE-A3 in A549 cells resulted in reduced cell migration. (F) Effect of MAGE-A3 knockdown on the expression of epithelial-mesenchymal transition markers was detected by qRT-PCR. All experiments were repeated $\geq 3$ times. Data were compared using paired two-tailed $t$-tests. ${ }^{*} \mathrm{P}<0.05,{ }^{* * *} \mathrm{P}<0.01,{ }^{* * *} \mathrm{P}<0.001 \mathrm{vs}$. the scrambled control group. MAGE, melanoma-associated antigen; si, small interfering RNA; EMT, epithelial-mesenchymal-transition marker; E-cad, epithelial-cadherin; N-cad, neural-cadherin; SLUG, snail family transcriptional repressor 2; Vim, vimentin; bp, base pairs; qPCR, quantitative polymerase chain reaction.

Effect of MAGE-A3 knockdown on A549 cell apoptosis and clonogenic survival. To investigate the biological effect of MAGE-A3 downregulation, siRNA knockdown of MAGE-A3 was performed and the growth phenotypes of A549 cells were examined. The effect of MAGE-A3 knockdown on cell apoptosis was determined through a PI-Annexin V assay. The knockdown of MAGE-A3 expression did not affect cell apoptosis $(\mathrm{P}=0.3592$; Fig. 3B). The ability of si-MAGE-A3-treated cells to form colonies 7 days following transfection was subsequently analyzed. The clonogenic cell survival assay assesses the ability of single cells to proliferate, and form independent and viable colonies. Knockdown of MAGE-A3 significantly reduced the colony-forming ability of A549 cells by $50 \%$ compared with control levels $(\mathrm{P}=0.0041$; Fig. 3C).

Effect of MAGE-A3 knockdown on A549 cell migration and EMT. Clinicopathological data analysis indicated that MAGE-A3 was involved in tumor metastasis. To confirm whether MAGE-A3 serves a role in the migration of A549 cells a Transwell migration assay was performed. The assay demonstrated that treatment with siRNA targeting MAGE-A3 significantly inhibited the migration of A549 cells $(\mathrm{P}=0.0098$; Fig. 3D and E). EMT influences the migration ability of tumor cells. Therefore, expression levels of several well-known EMT-associated factors [epithelial-cadherin (E-cadherin), neural-cadherin, vimentin and snail family transcriptional repressor 2] were measured. As expected, following si-MAGE-A3 treatment of A549 cells, the expression of E-cadherin was significantly increased compared with the control cells $(\mathrm{P}=0.0212$; Fig. 3F). In contrast, the expression of mesenchymal cell markers decreased significantly $(\mathrm{P}<0.05$; Fig. 3F). These results indicate that the regulation of expression of MAGE-A3 is associated with the EMT of tumor cells.

\section{Discussion}

Cancer-germline genes were first discovered and described in 1991 (34). Antigens encoded by cancer-germline genes are exclusively expressed within germ cells and a number of malignancies, making them attractive targets for cancer immunotherapy $(9,35,36)$. When selecting appropriate targets for cancer immunotherapy, it is important to consider the frequency of expression of the target within the cancer cells of interest. To improve the application and efficiency of immunotherapy for patients with NSCLC, it is necessary to determine the pattern and frequency of cancer-germline gene expression, in addition to the corresponding antigens encoded by these genes, in NSCLC samples. Numerous studies have investigated the expression of cancer-germline genes in NSCLC using IHC or RT-PCR $(15-17,19,37)$. However, to the best of our knowledge, the expression pattern of MAGE-C2 has not yet been investigated. In the present study, the expression of MAGE-A3, MAGE-C2 and their coexpression was investigated.

MAGE-A3 is one of the most commonly expressed cancer-germline genes in malignancies. It has been suggested that MAGE-A3 is expressed in $35-75 \%$ of patients with NSCLC, and is associated with advanced tumor stage and poor patient prognosis $(6,9,38,39)$. In the present study, the frequency of MAGE-A3 protein expression was decreased compared with that of MAGE-A3 mRNA in the tumor tissue of patients with NSCLC. Similar discrepancies between the expression of other MAGE mRNAs and proteins have been demonstrated in other types of cancer $(40,41)$. The lower 
frequency of protein expression may be due to the lower sensitivity of IHC compared with RT-PCR and variation between tumor samples. Thus, further studies are warranted to determine whether MAGE-A3 expression at the mRNA or protein level is a better predictor of the patients with NSCLC in which vaccination therapy will be most effective.

MAGE-A3 mRNA and protein expression was significantly correlated with lymph node metastasis in the present study, indicating that MAGE-A3 influences the ability of tumor cells to metastasize to lymph nodes. The results of the current study suggest that downregulation of MAGE-A3 expression reduces the ability of cells migrate through repressing mesenchymal and inducing epithelial cell phenotype. Knockdown of cancer-germline genes could alter cell migration, proliferation and EMT, which was consistent with the results of previous studies $(10,42)$. MAGE-A3 expression was significantly positively correlated with smoking history in patients with NSCLC, indicating that smoking may serve a role in DNA demethylation and the subsequent induction of MAGE-A3 expression. These results are similar to those of several previous studies (9,43-45). Smoking is known to be involved in cancer promotion and progression $(46,47)$. In addition, MAGE-A3-positive patients had a significantly poorer overall survival compared with MAGE-A3-negative patients. Multivariate analysis revealed that MAGE-A3 expression is an independent marker of poor prognosis in patients with NSCLC. MAGE-A3 is considered a potential target for NSCLC immunotherapy, particularly in advanced stage tumors, due to its relatively high level of expression in NSCLC. MAGE-A3-positive patients typically require further treatment following surgery and could benefit from immunotherapy targeting MAGE-A3.

MAGE-C2 belongs to the MAGE family of cancer-germline genes and has been proposed as a suitable candidate for immunotherapy in patients with hepatocellular carcinoma (29). MAGE-C2 has also been associated with tumor metastasis in breast cancer through inducing EMT (48). Previous studies have suggested a correlation between MAGE-C2 expression and advanced pathological tumor stage, in addition to poor prognosis, in different tumor types, including multiple myeloma and hepatocellular carcinoma $(24,29)$. In the present study, the frequency of MAGE-C2 expression was higher in male patients with NSCLC and in patients with an advanced tumor stage; however, no correlation was identified between MAGE-C2 expression and clinicopathological characteristics of NSCLC. The overall survival of MAGE-C2-positive patients was significantly decreased compared with MAGE-C2-negative patients. These results indicate that MAGE-C2 is a target for immunotherapy and a potential prognostic marker in patients with NSCLC.

Coexpression of MAGE-A3 and MAGE-C2 was significantly positively correlated with advanced tumor stage and poor patient prognosis. Several previous studies have indicated that the coexpression of MAGE-A3 and MAGE-C2 is correlated with advanced tumor stage and poor patient prognosis in a number of tumor types (49,50). Furthermore, combined polyvalent or sequential single vaccinations targeting multiple antigens encoded by cancer-germline genes could improve antitumor activity in NSCLC.

In conclusion, the present study identified a significant positive correlation between MAGE-A3 expression and tumor progression, in addition to poor patient prognosis. These results suggest that MAGE-A3 is a potential target for cancer immunotherapy. In addition, MAGE-A3 was identified to be an independent marker of poor prognosis in patients with NSCLC. A large proportion of patients with NSCLC, particularly patients with an advanced tumor stage who express MAGE-A3/C2, could benefit from vaccination with MAGE-A3/C2 antigens or antigen-specific TCR modified $\mathrm{T}$ cell therapy.

\section{Acknowledgements}

The present study was supported by the China-US Program for Biomedical Collaborative Research (grant no. 812111102), the National Natural Science Foundation of China (grant no. 81171986), the Ministry of Public Health (grant no. 20110110001), the Basic and Advanced Technology Research Foundation of the Science and Technology Department of Henan Province (grant nos. 112300410153 and 122300410155).

\section{References}

1. Jemal A, Bray F, Center MM, Ferlay J, Ward E and Forman D: Global cancer statistics. CA Cancer J Clin 61: 69-90, 2011.

2. Molina JR, Yang P, Cassivi SD, Schild SE and Adjei AA: Non-small cell lung cancer: Epidemiology, risk factors, treatment, and survivorship. Mayo Clin Proc 83: 584-594, 2008.

3. Quoix E, Lena H, Losonczy G, Forget F, Chouaid C, Papai Z, Gervais R, Ottensmeier C, Szczesna A and Kazarnowicz A: TG4010 immunotherapy and first-line chemotherapy for advanced non-small-cell lung cancer (TIME): Results from the phase $2 \mathrm{~b}$ part of a randomised, double-blind, placebo-controlled, phase 2b/3 trial. Lancet Oncol 17: 212-223, 2016.

4. Pinato DJ, Shiner RJ, White SD, Black JR, Trivedi P, Stebbing J, Sharma R and Mauri FA: Intra-tumoral heterogeneity in the expression of programmed-death (PD) ligands in isogeneic primary and metastatic lung cancer: Implications for immunotherapy. Oncoimmunology 5: e1213934, 2016.

5. Coulie PG, Van den Eynde BJ, van der Bruggen P and Boon T: Tumour antigens recognized by $\mathrm{T}$ lymphocytes: At the core of cancer immunotherapy. Nat Rev Cancer 14: 135-146, 2014.

6. Ulloa-Montoya F, Louahed J, Dizier B, Gruselle O, Spiessens B, Lehmann FF, Suciu S, Kruit WH, Eggermont AM, Vansteenkiste $\mathrm{J}$ and Brichard VG: Predictive gene signature in MAGE-A3 antigen-specific cancer immunotherapy. J Clin Oncol 31: 2388-2395, 2013

7. Rao M, Chinnasamy N, Hong JA, Zhang Y, Zhang M, Xi S, Liu F, Marquez VE, Morgan RA and Schrump DS: Inhibition of histone lysine methylation enhances cancer-testis antigen expression in lung cancer cells: Implications for adoptive immunotherapy of cancer. Cancer Res 71: 4192-4204, 2011.

8. Dobrynin P, Matyunina E, Malov SV and Kozlov AP: The novelty of human cancer/testis antigen encoding genes in evolution. Int J Genomics 2013: 105108, 2013.

9. Gure AO, Chua R, Williamson B, Gonen M, Ferrera CA, Gnjatic S, Ritter G, Simpson AJ, Chen YT, Old LJ and Altorki NK: Cancer-testis genes are coordinately expressed and are markers of poor outcome in non-small cell lung cancer. Clin Cancer Res 11: 8055-8062, 2005.

10. Koop A, Sellami N, Adam-Klages S, Lettau M, Kabelitz D, Janssen $\mathrm{O}$ and Heidebrecht HJ: Down-regulation of the cancer/testis antigen 45 (CT45) is associated with altered tumor cell morphology, adhesion and migration. Cell Commun Signal 11: 41, 2013.

11. Caballero OL, Cohen T, Gurung S, Chua R, Lee P, Chen YT, Jat $\mathrm{P}$ and Simpson AJ: Effects of CT-Xp gene knock down in melanoma cell lines. Oncotarget 4: 531-541, 2013.

12. Laban S, Atanackovic D, Luetkens T, Knecht R, Busch CJ, Freytag M, Spagnoli G, Ritter G, Hoffmann TK, Knuth A, et al: Simultaneous cytoplasmic and nuclear protein expression of melanoma antigen-A family and NY-ESO-1 cancer-testis antigens represents an independent marker for poor survival in head and neck cancer. Int J Cancer 135: 1142-1152, 2014. 
13. Andrade VC, Vettore AL, Regis Silva MR, Felix RS, Almeida MS de Carvalho F, Zago MA, Caballero OL, Simpson AJ and Colleoni GW: Frequency and prognostic relevance of cancer testis antigen 45 expression in multiple myeloma. Exp Hematol 37: 446-449, 2009.

14. Gotoh K, Yatabe Y, Sugiura T, Takagi K, Ogawa M, Takahashi T, Takahashi T and Mitsudomi T: Frequency of MAGE-3 gene expression in HLA-A2 positive patients with non-small cell lung cancer. Lung Cancer 20: 117-125, 1998.

15. Yanagawa N, Tamura G, Oizumi H, Endoh M and Motoyama T: MAGE mediated by demethylation of MAGE promoters induce progression of non-small cell lung cancer. Anticancer Res 31: 171-175, 2011.

16. Sienel W, Varwerk C, Linder A, Kaiser D, Teschner M, Delire M, Stamatis G and Passlick B: Melanoma associated antigen (MAGE)-A3 expression in Stages I and II non-small cell lung cancer: Results of a multi-center study. Eur J Cardiothorac Surg 25: 131-134, 2004

17. Tajima K, Obata Y, Tamaki H, Yoshida M, Chen YT, Scanlan MJ, Old LJ, Kuwano H, Takahashi T, Takahashi T and Mitsudomi T: Expression of cancer/testis (CT) antigens in lung cancer. Lung Cancer 42: 23-33, 2003.

18. Fourcade J, Sun Z, Pagliano O, Chauvin JM, Sander C, Janjic B, Tarhini AA, Tawbi HA, Kirkwood JM, Moschos S, et al: PD-1 and Tim-3 regulate the expansion of tumor antigen-specific $\mathrm{CD} 8^{+} \mathrm{T}$ cells induced by melanoma vaccines. Cancer Res 74: 1045-1055, 2014

19. Eikawa S, Kakimi K, Isobe M, Kuzushima K, Luescher I, Ohue Y, Ikeuchi K, Uenaka A, Nishikawa H, Udono H, et al: Induction of CD8 T-cell responses restricted to multiple HLA class I alleles in a cancer patient by immunization with a 20-mer NY-ESO-1f (NY-ESO-1 91-110) peptide. Int J Cancer 132: 345-354, 2013.

20. Cerfolio RJ and Bryant AS: Optimal care of patients with non-small cell lung cancer reduces perioperative morbidity. J Thorac Cardiovasc Surg 141: 22-33, 2011.

21. De Smet $\mathrm{C}$ and Loriot A: DNA hypomethylation and activation of germline-specific genes in cancer. Adv Exp Med Biol 754: 149-166, 2013.

22. de Carvalho F, Alves VL, Braga WM, Xavier CV Jr and Colleoni GW: MAGE-C1/CT7 and MAGE-C2/CT10 are frequently expressed in multiple myeloma and can be explored in combined immunotherapy for this malignancy. Cancer Immunol Immunother 62: 191-195, 2013.

23. Brichard VG and Godechal Q: MAGE-A3-specific anticancer immunotherapy in the clinical practice. Oncoimmunology 2: e25995, 2013

24. Pabst C, Zustin J, Jacobsen F, Luetkens T, Kröger N, Schilling G, Bokemeyer C, Sauter G, Atanackovic D and Marx A: Expression and prognostic relevance of MAGE-C1/CT7 and MAGE-C2/CT10 in osteolytic lesions of patients with multiple myeloma. Exp Mol Pathol 89: 175-181, 2010.

25. Straetemans T, van Brakel M, van Steenbergen S, Broertjes M, Drexhage J, Hegmans J, Lambrecht BN, Lamers C, van Der Bruggen P, Coulie PG and Debets R: TCR gene transfer: MAGE-C2/HLA-A2 and MAGE-A3/HLA-DP4 epitopes as melanoma-specific immune targets. Clin Dev Immunol 2012: 586314, 2012.

26. Ma W, Germeau C, Vigneron N, Maernoudt AS, Morel S, Boon T, Coulie PG and Van den Eynde BJ: Two new tumor-specific antigenic peptides encoded by gene MAGE-C2 and presented to cytolytic T lymphocytes by HLA-A2. Int J Cancer 109: 698-702, 2004.

27. Zhang Y, Sun Z, Nicolay H, Meyer RG, Renkvist N, Stroobant V, Corthals J, Carrasco J, Eggermont AM, Marchand M, et al: Monitoring of anti-vaccine CD4 T cell frequencies in melanoma patients vaccinated with a MAGE-3 protein. J Immunol 174: 2404-2411, 2005

28. Olarte I, Martinez A, Ramos-Peñafiel C, Castellanos-Sinco H, Zamora J, Collazo-Jaloma J, Gutiérrez M, Gutiérrez-Kobeh L, Chavez-Olmos P, Manzanilla $\mathrm{H}$, et al: MAGE-A3 expression is an adverse prognostic factor in diffuse large B-cell lymphoma. Hematology 16: 368-372, 2011.

29. Riener MO, Wild PJ, Soll C, Knuth A, Jin B, Jungbluth A, Hellerbrand C, Clavien PA, Moch $\mathrm{H}$ and Jochum W: Frequent expression of the novel cancer testis antigen MAGE-C2/CT-10 in hepatocellular carcinoma. Int J Cancer 124: 352-357, 2009.

30. Detterbeck FC, Postmus PE and Tanoue LT: The stage classification of lung cancer: Diagnosis and management of lung cancer 3rd ed: American college of chest physicians evidence-based clinical practice guidelines. Chest 143 (5 Suppl): e191S-e210S, 2013.
31. Sobin LH and Compton CC: TNM seventh edition: What's new, what's changed: Communication from the international union against cancer and the American joint committee on cancer. Cancer 116: 5336-5339, 2010

32. Livak KJ and Schmittgen TD: Analysis of relative gene expression data using real-time quantitative PCR and the 2(-Delta Delta C(T)) Method. Methods 25: 402-408, 2001.

33. Rapoport AP, Stadtmauer EA, Binder-Scholl GK, Goloubeva O, Vogl DT, Lacey SF, Badros AZ, Garfall A, Weiss B, Finklestein J, et al: NY-ESO-1-specific TCR-engineered T cells mediate sustained antigen-specific antitumor effects in myeloma. Nat Med 21: 914-921, 2015.

34. van der Bruggen $\mathrm{P}$, Traversari C, Chomez $\mathrm{P}$, Lurquin $\mathrm{C}$, De Plaen E, Van den Eynde B, Knuth A and Boon T: A gene encoding an antigen recognized by cytolytic $\mathrm{T}$ lymphocytes on a human melanoma. Science 254: 1643-1647, 1991.

35. Hofmann O, Caballero OL, Stevenson BJ, Chen YT, Cohen T, Chua R, Maher CA, Panji S, Schaefer U, Kruger A, et al: Genome-wide analysis of cancer/testis gene expression. Proc Natl Acad Sci USA 105: 20422-20427, 2008.

36. Caballero OL and Chen YT: Cancer/testis (CT) antigens: Potential targets for immunotherapy. Cancer Sci 100: 2014-2021, 2009.

37. Yoshida N, Abe H, Ohkuri T, Wakita D, Sato M, Noguchi D, Miyamoto M, Morikawa T, Kondo S, Ikeda $\mathrm{H}$ and Nishimura T: Expression of the MAGE-A4 and NY-ESO-1 cancer-testis antigens and $\mathrm{T}$ cell infiltration in non-small cell lung carcinoma and their prognostic significance. Int J Oncol 28: 1089-1098, 2006.

38. Kim YD, Park HR, Song MH, Shin DH, Lee CH, Lee MK and Lee SY: Pattern of cancer/testis antigen expression in lung cancer patients. Int J Mol Med 29: 656-662, 2012.

39. Pineda CT, Ramanathan S, Fon Tacer K, Weon JL, Potts MB, $\mathrm{Ou}$ YH, White MA and Potts PR: Degradation of AMPK by a cancer-specific ubiquitin ligase. Cell 160: 715-728, 2015.

40. Vaughan HA, Svobodova S, Macgregor D, Sturrock S, Jungbluth AA, Browning J, Davis ID, Parente P, Chen YT, Stockert E, et al: Immunohistochemical and molecular analysis of human melanomas for expression of the human cancer-testis antigens NY-ESO-1 and LAGE-1. Clin Cancer Res 10: 8396-8404, 2004.

41. Li M, Yuan YH,Han Y,Liu YX, Yan L, Wang Y and Gu J: Expression profile of cancer-testis genes in 121 human colorectal cancer tissue and adjacent normal tissue. Clin Cancer Res 11: 1809-1814, 2005.

42. Baia GS, Caballero OL, Ho JS, Zhao Q, Cohen T, Binder ZA, Salmasi V, Gallia GL, Quinones-Hinojosa A, Olivi A, et al: NY-ESO-1 expression in meningioma suggests a rationale for new immunotherapeutic approaches. Cancer Immunol Res 1: 296-302, 2013.

43. Grah J, Samija M, Juretić A, Sarcević B and Sobat H: Immunohystochemical expression of cancer/testis antigens (MAGE-A3/4, NY-ESO-1) in non-small cell lung cancer: The relationship with clinical-pathological features. Coll Antropol 32: 731-736, 2008.

44. Tan Q, Wang G, Huang J, Ding Z, Luo Q, Mok T, Tao Q and Lu S: Epigenomic analysis of lung adenocarcinoma reveals novel DNA methylation patterns associated with smoking. Onco Targets Ther 6: 1471-1479, 2013

45. Bhutani M, Pathak AK, Tang H, Fan YH, Liu DD, Lee JJ, Kurie J, Morice RC, Hong WK and Mao L: Frequent expression of MAGE1 tumor antigens in bronchial epithelium of smokers without lung cancer. Exp Ther Med 2: 137-142, 2011.

46. Chen RJ, Chang LW, Lin P and Wang YJ: Epigenetic effects and molecular mechanisms of tumorigenesis induced by cigarette smoke: An overview. J Oncol 2011: 654931, 2011.

47. Park SY, Lee JG, Kim J, Bae MK, Lee CY, Kim DJ and Chung KY: The influence of smoking intensity on the clinicopathologic features and survival of patients with surgically treated non-small cell lung cancer. Lung Cancer 81: 480-486, 2013.

48. Yang F, Zhou X, Miao X, Zhang T, Hang X, Tie R, Liu N, Tian F, Wang F and Yuan J: MAGEC2, an epithelial-mesenchymal transition inducer, is associated with breast cancer metastasis. Breast Cancer Res Treat 145: 23-32, 2014.

49. Chen X, Wang L, Yue D, Liu J, Huang L, Yang L, Cao L, Qin G, Li A, Wang D, et al: Correlation between the high expression levels of cancer-germline genes with clinical characteristics in esophageal squamous cell carcinoma. Histol Histopathol: 11847, 2016.

50. Andrade VC, Vettore AL, Felix RS, Almeida MS, Carvalho F, Oliveira JS, Chauffaille ML, Andriolo A, Caballero OL, Zago MA and Colleoni GW: Prognostic impact of cancer/testis antigen expression in advanced stage multiple myeloma patients. Cancer Immun 8: 2, 2008. 